\title{
Recent advances in the molecular mechanisms of Mayer-Rokitansky-Küster-Hauser syndrome (Review)
}

\author{
KEIKO WATANABE, YUSUKE KOBAYASHI, KOUJI BANNO, \\ YUSUKE MATOBA, HARUKO KUNITOMI, KANAKO NAKAMURA, MASATAKA ADACHI, \\ KIYOKO UMENE, IORI KISU, EIICHIRO TOMINAGA and DAISUKE AOKI \\ Department of Obstetrics and Gynecology, Keio University School of Medicine, Tokyo 160-8582, Japan
}

Received February 6, 2017; Accepted May 11, 2017

DOI: $10.3892 /$ br.2017.929

\begin{abstract}
Mayer-Rokitansky-Küster-Hauser syndrome (MRKHS) is a disease caused by congenital absence of the uterus and two-thirds of the upper vagina. The pathogenic mechanism of MRKHS may involve gene abnormalities, and there are various case reports associating MRKHS with the Wnt family member 4 (Wnt4) mutation. Analysis of genes mapped to regions in which deletion and duplication are frequently detected in patients with MRKHS has shown involvement of LIM homeobox 1 ( LHX1), HNF1 homeobox B (HNF1B) and T-box 6 (TBX6). In addition, there are case reports of MRKHS caused by chromosomal translocation and epigenetic function may be involved in MRKHS onset. Overexpression of HOXA and overexposure to estrogen may contribute to the onset and regulation of expression by methylation as a pathogenic mechanism. Determination of the molecular basis of MRKHS is in progress, but current treatment only includes vaginal enlargement and vaginoplasty for improved quality of life. Clinical application of uterine transplantation to allow childbearing by MRKHS patients is under investigation and clinical trials are underway around the world.
\end{abstract}

\section{Contents}

1. Introduction

2. MRKHS and gene mutation

3. Chromosomal translocation in MRKHS

4. MRKHS and epigenetic abnormalities

5. Clinical practice for MRKHS

6. Expected treatment with uterine transplantation

7. Conclusion

Correspondence to: Dr Kouji Banno, Department of Obstetrics and Gynecology, Keio University School of Medicine, 35 Shinanomachi Shinjuku-ku, Tokyo 160-8582, Japan

E-mail:kbanno@z7.keio.jp

Key words: Mayer-Rokitansky-Küster-Hauser syndrome, epigenetics, methylation, uterus, vagina, uterine transplantation

\section{Introduction}

Mayer-Rokitansky-Küster-Hauser syndrome (MRKHS) is a disease caused by congenital absence of the uterus and two-thirds of the upper vagina (1). Women with MRKHS develop normal secondary sexual characteristics and have a female chromosome pattern (46,XX) (1). MRKHS occurs in one in 4,500 women globally (1) and is the second leading cause of primary amenorrhea (2). Numerous women with MRKHS experience uterine pregnancy. The syndrome consists of sporadic type I and type II forms associated with renal and skeletal malformation, as well as auditory disorders $(3,4)$. Types I and II MRKHS account for 44 and $56 \%$ of all cases, respectively (5). MRKHS was previously considered as a sporadic disease (1) and the cause was unknown for many years. To date, there are only 68 cases of familial MRKHS reported (6).

Prenatal diagnosis and genetic counseling are not considered useful due to the apparently sporadic nature of MRKHS (1). MRKHS is rare congenital disease, therefore, the molecular mechanism remains unclear. However, recent studies have identified causative genes for MRKHS. Furthermore, in monozygotic twins, one develops MRKHS and the other does not, which is due to differences in phenotype. This indicates that the pathogenesis of MRKHS is associated with epigenetic mechanisms linked to environmental and stochastic factors (7).

To understand the potential molecular mechanisms of MRKHS in detail, a comprehensive literature search was conducted up to December 2016 using the Pubmed database. The following search terms were used: 'Mayer-Rokitansky-Küster-Hauser syndrome', 'MRKHS', 'Mullerian agenesis/aplasia', 'Mullerian agenesis/aplasia', 'vaginal agenesis/aplasia', 'uterine agenesis/aplasia', 'transplantation'. To the best of our knowledge, the current review is the first to analyze MRKHS at the genetic level.

\section{MRKHS and gene mutation}

Certain studies have described MRKHS as a multifactorial disorder; however, onset of MRKHS is predominantly caused by a single gene mutation. Based on the observation that the Mullerian duct was not formed in Wnt family member 4 (Wnt4) knockout mice (8), Biason-Lauber et al (9) conducted a genetic 
analysis in 18-year-old patients with MRKHS and showed that the Wnt4 mutation also occurred in women with MRKHS (9). Wnt4 mutation inhibits repression of ovarian steroid enzymes and causes abnormal expression of $17 \alpha$ hydroxylase (10), causing these patients to exhibit hyperandrogenism. However, only four patients with MRKHS were found to have Wnt4 mutations (9-11) and a cohort study in patients with genital development anomalies failed to show the Wnt4 mutation (12).

Analysis of the function of genes mapped to regions in which deletion and duplication are frequently detected in patients with MRKHS has led to identification of the involvement of LIM homeobox 1 (LHX1), HNF1 homeobox B $(H N F 1 B)$ and T-box $6(T B X 6)$ in early development of the disease. $L H X 1$ is necessary for formation of the Mullerian duct-derived uterine and vaginal epithelia (13). Ledig et al (14) found chromosome 17q12 deletion, including loss of $L H X 1$, in $6 \%$ of patients with MRKHS. HNF1B, which is also on chromosome 17q12 (14), is a Pit-Oct-Unc homeodomain transcription factor that is frequently expressed in the Mullerian duct during development (15). Haploinsufficiency of $H N F 1 B$ causes $L H X I$ downregulation and uterine hypoplasia, and chromosome 16 p11.2 deletion induces MRKHS due to loss of the transcription factor. TBX6 is involved in paraxial mesoderm formation and somitogenesis in human embryos (16). Splicing variants and missense mutations of the above-mentioned genes have also been observed in patients with MRKHS $(17,18)$.

\section{Chromosomal translocation in MRKHS}

To the best of our knowledge, there are only 4 case reports of MRKHS that may have been caused by chromosomal translocation. These include two $\mathrm{t}(8 ; 13)(\mathrm{q} 12 ; \mathrm{q} 14)$ cases reported in 1988 (19) and a t(8;13)(q22.1;q32.1) case described in 1999 (20), all of which were analyzed before use of chromosomal microarray analysis; therefore, the chromosomal breakpoint was not identified. In 2016, Williams et al (21) examined the genes of a 17-year-old Caucasian female with hypoplasia of the uterus and vagina, with MRKHS and genotype $(46, \mathrm{XX})$. None of her family had MRKHS. A t $(3 ; 16)(\mathrm{p} 22.3 ; \mathrm{p} 13.3)$ translocation was identified. This genetic analysis indicated that the breakpoint was CKLF like MARVEL transmembrane domain containing 7 (CMTM7) in chromosome 3p22 and interleukin 3 (IL3) in chromosome 16p13.3. Based on these results, 10 genes [tripartite motif containing 71 (TRIM71), CCR4-NOT transcription complex subunit 10 (CNOT10), olfactory receptor family 1 subfamily $\mathrm{F}$ member 1 (ORIF1), zinc finger protein 213 (ZNF213), ZNF200, ZNF205, CMTM7, C-C motif chemokine receptor 4 (CCR4), IL32 and MEFV, pyrin innate immunity regulator] were identified as possibly involved in MRKHS (21). However, the requirement for additional cohort studies was highlighted due to these results, which were obtained from an analysis of a single patient with MRKHS (Table I).

\section{MRKHS and epigenetic abnormalities}

It has been identified that one of monozygotic twins develops MRKHS and the other does not, which indicates that the disease is due to differences in phenotype. Therefore, the pathogenic mechanism of MRKHS may involve epigenetic changes due to environmental and stochastic factors (7). Rall et al (22) investigated differences in transcription products and methylation levels between patients with MRKHS and healthy volunteers using genome-wide analyses. Microarray analysis revealed 293 transcription products with different expression levels and $194 \mathrm{CpG}$ islands with different methylation patterns, compared with those in healthy volunteers. By evaluating two gene clusters, nine potentially causative genes [homeobox A5 (HOXA5), HOXA9, WNT1 inducible signaling pathway protein 2 (WISP2), cadherin 5 (CDH5), paternally expressed 10 (PEG10), microfibrillar associated protein 5 (MFAP5), leucine rich repeat containing 32 ( $L R R C 32)$, Ral GEF with PH domain and SH3 binding motif 2 (RALGPS2) and sphingomyelin phosphodiesterase 3 (SMPD3)] were identified. Six of these genes (CDH5, MFAP5, WISP2, HOXA5, PEG10 and HOXA9) are involved in development of female genitalia. Subsequent network analyses identified WISP2, HOXA5, HOXA9, GATA binding protein 4 (GATA4) and Wilms tumor 1 (WT1) as key genes in MRKHS (Table II).

WT1 and GATA4 regulate sex determination and differentiation via anti-Mullerian hormone (AMH) (23). WT1 and GATA4 are demethylated in patients with MRKHS when compared with healthy volunteers. WT1 and GATA4 promote AMH expression, leading to the degeneration of the Mullerian duct. Activating mutation of either the gene for the AMH receptor, resulting in the inappropriate excessive production of $\mathrm{AMH}$, or the receptor itself, is the underlying cause of MRKHS (22). HOXA9 is expressed in the region that becomes the oviduct (24); exposure to diethylstilbestrol produces ectopic expression of HOXA9, leading to developmental anomaly of the upper Mullerian duct $(24,25)$. Furthermore, HOXA5 is a transcription factor of p53 and progesterone receptor (26). Ectopic expression of $H O X A 5$, similarly to $H O X A 9$, inhibits Mullerian duct differentiation (27).

WISP2 is significant in smooth muscle cell proliferation and migration, and is induced by estrogen in the uterus (28). Estrogen regulates $A M H$ expression levels (29) and overexposure to estrogen during development activates $A M H$ promotors (22). Exposure of a fetus to endocrine-disrupting chemicals in the uterus and abnormally high levels of maternal hormones contributes to ectopic expression of $H O X A$ genes. Rall et al (22) suggested that overexposure to estrogen and ectopic expression of $H O X A$ may lead to female genital hypoplasia and cause MRKHS. However, it was noted that other factors may also activate the $A M H$ promoter and further studies are required.

\section{Clinical practice for MRKHS}

Treatment of MRKHS includes vaginal enlargement and vaginoplasty to enable sexual behavior, surrogate delivery, and uterine transplantation for patients who wish to have a child. The major methods are the Frank method (30) of inserting a device into the vagina that gradually enlarges the vagina, and the Ingram method (31), which uses a device to enlarge the vagina using the patient's body weight. Vaginal enlargement is performed prior to vaginoplasty and many patients request vaginoplasty due to insufficient sexual satisfaction (30). Vaginal enlargement may be achieved using the Vecchietti method of traction using olive-shaped beads, the Davydov 
Table I. Chromosomal translocations in MRKHS.

\begin{tabular}{llll}
\hline Author, year & Translocation site & Onset & Phenotype \\
\hline Kucheria et al, 1988 & $\mathrm{t}(8 ; 13)(\mathrm{q} 12 ; \mathrm{q} 14)$ & Unknown & MRKHS \\
& $\mathrm{t}(8 ; 13)(\mathrm{q} 12 ; \mathrm{q} 14)$ & Unknown & MRKHS, renal hypoplasia \\
Amesse et al, 1999 & $\mathrm{t}(8 ; 13)(\mathrm{q} 22.1 ; \mathrm{q} 32.1)$ & Sporadic & $\begin{array}{l}\text { MRKHS, amastia, amelia, urine reflux, } \\
\text { urinary incontinence }\end{array}$ \\
Williams et al, 2016 & $\mathrm{t}(3 ; 16)(\mathrm{p} 22.3 ; \mathrm{p} 13.3)$ & Sporadic & MRKHS
\end{tabular}

MRKHS, Mayer-Rokitansky-Küster-Hauser syndrome.

Table II. Epigenetic abnormalities in MRKHS.

\begin{tabular}{|c|c|c|c|c|}
\hline Author, year & Gene & Locus & Function & Refs. \\
\hline \multirow[t]{2}{*}{ Miyamoto, 2008} & Wilms tumor gene 1 (WT1) & $11 \mathrm{p} 13$ & $\begin{array}{l}\text { Sexual determination and } \\
\text { control of sexual differentiation }\end{array}$ & $(23)$ \\
\hline & GATA-binding protein 4 (GATA4) & $8 \mathrm{p} 23.1$ & $\begin{array}{l}\text { Sexual determination and } \\
\text { control of sexual differentiation }\end{array}$ & $(23)$ \\
\hline Taylor, 2008 & Homeobox A9 (HOXA9) & $7 \mathrm{p} 15.2$ & Fallopian tube development & $(24)$ \\
\hline Sauter et al, 2005 & Homeobox A5 (HOXA5) & $7 \mathrm{p} 15.2$ & Transcriptional regulation of p53 & $(26)$ \\
\hline Mason et al, 2004 & $\begin{array}{l}\text { WNT1 inducible signaling } \\
\text { pathway protein } 2 \text { (WISP2) }\end{array}$ & $20 q 13.12$ & $\begin{array}{l}\text { Smooth muscle cell } \\
\text { proliferation and migration }\end{array}$ & $(28)$ \\
\hline
\end{tabular}

MRKHS, Mayer-Rokitansky-Küster-Hauser syndrome.

method of laparoscopically forming the vagina using the peritoneum, the McIndoe method of forming the vagina by skin grafting, and the Sigmoid method, which uses the sigmoid colon (30).

Surrogate delivery is an option for patients with MRKHS who want to have a biological child because they have normal ovarian function (1). Friedler et al (32) described 125 patients with MRKHS who underwent in vitro fertilization, with 71 infants born by surrogate delivery worldwide. To the best of our knowledge, there are no case reports regarding the birth of a girl with MRKH to a mother with MRKHS (32). Surrogate delivery is formally prohibited in Europe, whereas there is no legal regulation of surrogate delivery in Japan (33). However, the Japan Society of Obstetrics and Gynecology does not permit surrogate delivery, as the wellbeing of children should be placed above all else. Surrogate delivery has many problems, including the physical and mental load on the surrogate mother, complicated family relations due to surrogate delivery, and negative social opinions surrounding the contract for surrogate delivery (33).

\section{Expected treatment with uterine transplantation}

Uterine transplantation is another option for patients who desire to have a child. Brännström et al (34) reported the case of a patient (age, 35 years) with MRKHS who received a uterus from a 61-year-old woman who had delivered two children (34). In vitro fertilization was performed using the patient's ova and sperm from her partner. One year after uterine transplantation, she successfully underwent embryo implantation and had a male infant (body weight, $1,775 \mathrm{~g}$ ) at 31 weeks and 5 days gestation. Thus, patients with MRKHS have successfully undergone uterine transplantation (34). In Japan, uterine transplantation has been examined in cynomolgus monkeys $(35,36)$. The uterus was exchanged between two cynomolgus monkeys and one successfully achieved natural pregnancy following menstruation (36). In cynomolgus monkeys, uterine atrophy occurred subsequent to uterine transplantation. It remains unclear as to why uterine transplantation causes uterine atrophy, although insufficient uterine blood flow is assumed to be one of the reasons for these issues. Uterine blood flow is significant in uterine viability, therefore two technical proedures were examined in the cynomolgus monkeys. The first method was indocyanine green (ICG) fluorescence imaging for evaluation of uterine blood flow $(37,38)$. ICG fluorescence imaging, an angiographic technique that is simple to use and minimally invasive, enabled intraoperative real-time evaluation of uterine hemodynamics. The second method involves use of the ovarian vein rather than the uterine vein as an anastomosis blood vessel (38). The ovarian vein is a thick vessel that runs along the upper part of the pelvis, and previous reports demonstrate that the ovarian vein may contribute to drainage of the uterus to a great extent (37-41). The vascular anastomosis with larger diameter leads to less complicated surgery, and the warm ischemic time is effectively reduced (39). Furthermore, use of the ovarian vein appears to 
be less invasive and safer for donors (38). Another concern is pregnancy-induced hypertension following uterine transplantation. Certain reports demonstrate that the incidence of pregnancy-induced hypertension appears to be higher in liver and renal transplantation patients versus the general population $(42,43)$. Pregnancies following organ transplantation carry a high risk of pregnancy-induced hypertension, which indicates that insufficient uterine blood flow, organ rejection or administration of immunosuppressive drugs may lead to hypertension.

Thus, clinical studies regarding uterine transplantation are advanced in many countries and application in humans is anticipated in the near future.

\section{Conclusion}

Recent studies have shown that the pathogenic mechanisms of MRKHS include single-gene mutations and epigenetic changes. Determination of the cause of MRKHS is in progress; however, prenatal diagnosis and genetic counseling are currently less useful. Vaginal enlargement and vaginoplasty are performed as treatment strategies for MRKHS, although such treatment does not lead to fertility. Clinical application of uterine transplantation may be the solution for patients with MRKHS who hope to deliver a biological child following gestation within the uterus.

\section{References}

1. Nodale C, Ceccarelli S, Giuliano M, Cammarota M, D'Amici S, Vescarelli E, Maffucci D, Bellati F, Panici PB, Romano F, et al: Gene expression profile of patients with Mayer-Rokitansky-Küster-Hauser syndrome: New insights into the potential role of developmental pathways. PLoS One 9: e91010, 2014.

2. Fontana L, Gentilin B, Fedele L, Gervasini C and Miozzo M: Genetics of Mayer-Rokitansky-Küster-Hauser (MRKH) syndrome. Clin Genet 91: 233-246, 2017.

3. Duncan PA, Shapiro LR, Stangel JJ, Klein RM and Addonizio JC: The MURCS association: Müllerian duct aplasia, renal aplasia, and cervicothoracic somite dysplasia. J Pediatr 95: 399-402, 1979.

4. Hofstetter G, Concin N, Marth C, Rinne T, Erdel M and Janecke A: Genetic analyses in a variant of Mayer-Rokitansky-Kuster-Hauser syndrome (MURCS association). Wien Klin Wochenschr 120 435-439, 2008

5. Strübbe EH, Cremers CW, Willemsen WN, Rolland R and Thijn CJ: The Mayer-Rokitansky-Küster-Hauser (MRKH) syndrome without and with associated features: Two separate entities? Clin Dysmorphol 3: 192-199, 1994.

6. Herlin M, Højland AT and Petersen MB: Familial occurrence of Mayer-Rokitansky-Küster-Hauser syndrome: A case report and review of the literature. Am J Med Genet A 164A: 2276-2286, 2014.

7. Gervasini C, Grati FR, Lalatta F, Tabano S, Gentilin B, Colapietro P, De Toffol S, Frontino G, Motta F, Maitz S, et al: SHOX duplications found in some cases with type I Mayer-Rokitansky-Kuster-Hauser syndrome. Genet Med 12: 634-640, 2010

8. Vainio S, Heikkilä M, Kispert A, Chin N and McMahon AP: Female development in mammals is regulated by Wnt-4 signalling. Nature 397: 405-409, 1999.

9. Biason-Lauber A, Konrad D, Navratil F and Schoenle EJ: A WNT4 mutation associated with Müllerian-duct regression and virilization in a 46,XX woman. N Engl J Med 351: 792-798, 2004.

10. Philibert P, Biason-Lauber A, Gueorguieva I, Stuckens C, Pienkowski C, Lebon-Labich B, Paris F and Sultan C: Molecular analysis of WNT4 gene in four adolescent girls with mullerian duct abnormality and hyperandrogenism (atypical Mayer-Rokitansky-Küster-Hauser syndrome). Fertil Steril 95: 2683-2686, 2011.
11. Ravel C, Lorenço D, Dessolle L, Mandelbaum J, McElreavey K, Darai E and Siffroi JP: Mutational analysis of the WNT gene family in women with Mayer-Rokitansky-Kuster-Hauser syndrome. Fertil Steril 91 (Suppl): 1604-1607, 2009.

12. Domenice S, Corrêa RV, Costa EM, Nishi MY, Vilain E, Arnhold IJ and Mendonca BB: Mutations in the SRY, DAX1, SF1 and WNT4 genes in Brazilian sex-reversed patients. Braz J Med Biol Res 37: 145-150, 2004

13. Kobayashi A, Shawlot W, Kania A and Behringer RR: Requirement of Lim1 for female reproductive tract development. Development 131: 539-549, 2004.

14. Ledig S, Brucker S, Barresi G, Schomburg J, Rall K and Wieacker P: Frame shift mutation of LHX1 is associated with Mayer-Rokitansky-Kuster-Hauser (MRKH) syndrome. Hum Reprod 27: 2872-2875, 2012.

15. Coffinier C, Barra J, Babinet $\mathrm{C}$ and Yaniv M: Expression of the vHNF1/HNF1beta homeoprotein gene during mouse organogenesis. Mech Dev 89: 211-213, 1999.

16. Yi CH, Terrett JA, Li QY, Ellington K, Packham EA, Armstrong-Buisseret L, McClure P, Slingsby T and Brook JD: Identification, mapping, and phylogenomic analysis of four new human members of the T-box gene family: EOMES, TBX6, TBX18, and TBX19. Genomics 55: 10-20, 1999.

17. Sandbacka M, Laivuori H, Freitas É, Halttunen M, Jokimaa V, Morin-Papunen L, Rosenberg C and Aittomäki K: TBX6, LHX1 and copy number variations in the complex genetics of Müllerian aplasia. Orphanet J Rare Dis 8: 125, 2013.

18. Waschk DE, Tewes AC, Römer T, Hucke J, Kapczuk K, Schippert C, Hillemanns P, Wieacker P and Ledig S: Mutations in WNT9B are associated with Mayer-Rokitansky-Küster-Hauser syndrome. Clin Genet 89: 590-596, 2016.

19. Kucheria K, Taneja N and Kinra G: Autosomal translocation of chromosomes 12q \& 14q in mullerian duct failure. Indian J Med Res 87: 290-292, 1988.

20. Amesse L, Yen FF, Weisskopf B and Hertweck SP: Vaginal uterine agenesis associated with amastia in a phenotypic female with a de novo $46, \mathrm{XX}, \mathrm{t}(8 ; 13)(\mathrm{q} 22.1 ; \mathrm{q} 32.1)$ translocation. Clin Genet 55: 493-495, 1999.

21. Williams LS, Kim HG, Kalscheuer VM, Tuck JM, Chorich LP, Sullivan ME, Falkenstrom A, Reindollar RH and Layman LC: A balanced chromosomal translocation involving chromosomes 3 and 16 in a patient with Mayer-Rokitansky-Kuster-Hauser syndrome reveals new candidate genes at $3 \mathrm{p} 22.3$ and $16 \mathrm{p} 13.3$. Mol Cytogenet 9: 57, 2016.

22. Rall K, Barresi G, Walter M, Poths S, Haebig K, Schaeferhoff K, Schoenfisch B, Riess O, Wallwiener D, Bonin M, et al: A combination of transcriptome and methylation analyses reveals embryologically-relevant candidate genes in MRKH patients. Orphanet J Rare Dis 6: 32, 2011.

23. Miyamoto Y, Taniguchi H, Hamel F, Silversides DW and Viger RS: A GATA4/WT1 cooperation regulates transcription of genes required for mammalian sex determination and differentiation. BMC Mol Biol 9: 44, 2008.

24. Taylor HS: Endocrine disruptors affect developmental programming of HOX gene expression. Fertil Steril 89: e57-e58, 2008.

25. Suzuki A, Urushitani H, Sato T, Kobayashi T, Watanabe H, Ohta Y and Iguchi T: Gene expression change in the Müllerian duct of the mouse fetus exposed to diethylstilbestrol in utero. Exp Biol Med (Maywood) 232: 503-514, 2007.

26. Sauter CN, McDermid RL, Weinberg AL, Greco TL, Xu X, Murdoch FE and Fritsch MK: Differentiation of murine embryonic stem cells induces progesterone receptor gene expression. Exp Cell Res 311: 251-264, 2005.

27. Aubin J, Lemieux M, Tremblay M, Behringer RR and Jeannotte L: Transcriptional interferences at the Hoxa4/Hoxa5 locus: Importance of correct Hoxa5 expression for the proper specification of the axial skeleton. Dev Dyn 212: 141-156, 1998.

28. Mason HR, Lake AC, Wubben JE, Nowak RA and Castellot JJ Jr: The growth arrest-specific gene CCN5 is deficient in human leiomyomas and inhibits the proliferation and motility of cultured human uterine smooth muscle cells. Mol Hum Reprod 10: 181-187, 2004.

29. Chen G, Shinka T, Kinoshita K, Yan HT, Iwamoto T and Nakahori Y: Roles of estrogen receptor alpha (ER alpha) in the regulation of the human Müllerian inhibitory substance (MIS) promoter. J Med Invest 50: 192-198, 2003.

30. Bombard DS II and Mousa SA: Mayer-Rokitansky-Kuster-Hauser syndrome: complications, diagnosis and possible treatment options: A review. Gynecol Endocrinol 30: 618-623, 2014. 
31. Lee MH: Non-surgical treatment of vaginal agenesis using a simplified version of Ingram's method. Yonsei Med J 47: 892-895, 2006.

32. Friedler S, Grin L, Liberti G, Saar-Ryss B, Rabinson Y and Meltzer S: The reproductive potential of patients with Mayer-Rokitansky-Küster-Hauser syndrome using gestational surrogacy: A systematic review. Reprod Biomed Online 32: 54-61, 2016.

33. Kisu I, Banno K, Mihara M, Iida T and Yoshimura Y: Current status of surrogacy in Japan and uterine transplantation research. Eur J Obstet Gynecol Reprod Biol 158: 135-140, 2011.

34. Brännström M, Johannesson L, Bokström H, Kvarnström N, Mölne J, Dahm-Kähler P, Enskog A, Milenkovic M, Ekberg J, Diaz-Garcia C, et al: Livebirth after uterus transplantation. Lancet 385: 607-616, 2015.

35. Kisu I, Mihara M, Banno K, Hara H, Masugi Y, Araki J, Iida T, Yamada Y, Kato Y, Shiina T, et al: Uterus allotransplantation in cynomolgus macaque: A preliminary experience with non-human primate models. J Obstet Gynaecol Res 40: 907-918, 2014.

36. Mihara M, Kisu I, Hara H, Iida T, Araki J, Shim T, Narushima M, Yamamoto T, Moriguchi H, Kato Y, et al: Uterine autotransplantation in cynomolgus macaques: The first case of pregnancy and delivery. Hum Reprod 27: 2332-2340, 2012.

37. Kisu I, Banno K, Mihara M, Lin LY, Tsuji K, Yanokura M, Hara H, Araki J, Iida T, Abe T, et al: Indocyanine green fluorescence imaging for evaluation of uterine blood flow in cynomolgus macaque. PLoS One 7: e35124, 2012.
38. Kisu I, Banno K, Mihara M, Hara H, Umene K, Adachi M, Nogami Y and Aoki D: A surgical technique using the ovarian vein in non-human primate models of potential living-donor surgery of uterus transplantation. Acta Obstet Gynecol Scand 94: 942-948, 2015

39. Obara H, Kisu I, Kato Y, Yamada Y, Matsubara K, Emoto K, Adachi M, Matoba Y, Umene K, Nogami Y, et al: Surgical technique for allogeneic uterus transplantation in macaques. Sci Rep 6: 35989, 2016.

40. Kin Y,Katsumori T, Kasahara T, Nozaki T, Ito H and Nishimura T: Hemodynamics of ovarian veins: MR angiography in women with uterine leiomyomata. Eur J Radiol 63: 408-413, 2007.

41. Asayama Y, Yoshimitsu K, Aibe H, Nishie A, Kakihira D, Irie H, Tajima T, Matake K, Nakayama T, Ohishi Y, et al: MDCT of the gonadal veins in females with large pelvic masses: Value in differentiating ovarian versus uterine origin. AJR Am J Roentgenol 186: 440-448, 2006.

42. Shah S and Verma P: Overview of Pregnancy in Renal Transplant Patient. Int J Nephrol 2016: 4539342, 2016.

43. Kubo S, Uemoto S, Furukawa H, Umeshita K and Tachibana D; Japanese Liver Transplantation Society: Pregnancy outcomes after living donor liver transplantation: Results from a Japanese survey. Liver Transpl 20: 576-583, 2014. 